\title{
Lewis-Mogridge Points: A Nonarbitrary Method to Include Induced Traffic in Cost-Benefit Analyses
}

\author{
Rafał Kucharski $\mathbb{D}^{1},{ }^{1}$ Arkadiusz Drabicki, ${ }^{1}$ Jan Paszkowski, ${ }^{1,2}$ and Andrzej Szarata $\mathbb{D}^{1}$ \\ ${ }^{1}$ Politechnika Krakowska, Warszawska 24, Kraków 31-155, Poland \\ ${ }^{2}$ Westsächsische Hochschule Zwickau, Dr.-Friedrichs-Ring 2A, Zwickau 08056, Germany \\ Correspondence should be addressed to Rafał Kucharski; rkucharski@pk.edu.pl
}

Received 18 December 2018; Accepted 27 December 2019; Published 10 March 2020

Academic Editor: Jose E. Naranjo

Copyright (C) 2020 Rafał Kucharski et al. This is an open access article distributed under the Creative Commons Attribution License, which permits unrestricted use, distribution, and reproduction in any medium, provided the original work is properly cited.

\begin{abstract}
We propose a new method to estimate benefits of road network improvements, which allows to include the induced demand without arbitrary assumptions. Instead of estimating induced demand (which is nontrivial and hardly possible in practice), we search for demand induction where initial benefits are mitigated to zero. Such approach allows to formulate a dual measure of benefit, covering both the potential benefits and the likelihood of consuming them by the induced traffic. We first estimate benefits of road network improvement assuming that traffic demand is fixed. Consequently, we find demand model configurations at which the benefits of the new investment become null, i.e., all the initial benefits are consumed by the traffic demand growth. We call such states of induced demand the Lewis-Mogridge points of the analysed improvement. We select the most probable of such points and use it to calculate the proposed novel indicator $\mu$, for which the initial benefits (obtained under a fixed-demand assumption) are multiplied with a demand increase rate needed to consume them. We believe that such measure allows to include the critical phenomena of induced traffic and, at the same time, to overcome problems associated with reliable estimation of induced demand. As we illustrate with the case of two alternative road improvement schemes in Kraków, Poland, the proposed method allows to estimate maximal threshold of induced traffic and to select scenario more resilient to induced traffic.
\end{abstract}

\section{Introduction}

Induced (generated) traffic, spurred by improvements in road networks, is nowadays a recognised phenomenon in transportation planning practice, especially in case of largescale development projects. It either may result from new road projects (new network links) or upgrades to current network (existing network links) such as carriageway widening and construction of grade-separated junctions. These projects substantially alter the existing travel conditions and accessibility levels and thus facilitate additional growth in trip volumes in the network. Ample research and empirical evidence indicate that changes in the level (quality) of service resultant, e.g., from road improvements, are likely to encourage shifts in long-term mobility patterns and activity chains [1-3]. Such changes may lead to extra growth in road traffic, which would not otherwise occur and possibly may contribute to even worse road congestion [4]. This resembles the classical economic law of supply demand, which states that decreasing cost on the supply side (i.e., generalised cost of travel) encourages further demand for that particular good/service (i.e., travel activities) [5].

A key challenge in road appraisal process is how to predict what shift in mobility patterns will be induced by the analysed road network changes. Such estimates are crucial to properly assess the actual benefits of road investments, which might be often overestimated due to a fixed-demand assumption [5]. To overcome this overestimation risk, the notion of demand elasticity (flexibility) is typically incorporated in analytical models. This implies that travel demand becomes a function of supply, i.e., traffic volumes being flexible and sensitive to road network improvements [6]. Such approach allows to estimate the actual changes in travel behaviour and include them in cost-benefit analysis (CBA) 
estimations. Unfortunately, such methods require solid empirical support and the results strongly rely on the model parametrization. In practice, reliable data on demand elasticity seem to be either available only ex-post (i.e., when making short- and long-term observations of induced traffic) or are assumed arbitrarily (i.e., when making assumptions analogous to similar investments or using stated preferences, often biased by user responses). Wide variety of projects altering the topology and parameters of road network calls for detailed analysis of induced traffic. This may refer to new investments, including new links (roads, bridges, and tunnels), as well as changes in existing infrastructure, both upgrades (widening and improving) and downgrades (narrowing and restricting).

This raises an issue that we address in this paper, namely, instead of assessing implications of various demand model scenarios, which are often formulated arbitrarily (which seems a predominant approach in practice), we analyse when the benefits become null due to traffic growth. To this end, we propose a method where we hypothesize that Lewis-Mogridge position holds true and we try to determine the likelihood of this hypothesis. As we will show below, this allows to overcome the limitations of arbitrary induceddemand assumptions and, hence, to formulate a novel measure covering both the potential benefits and probability of them being consumed (eroded) in long term due to induced traffic.

This paper is organised as follows. Section 2 provides literature review on induced traffic, comprising general systematics, methodology, popular paradoxes, and positions, including the Lewis-Mogridge position, central to this paper. We review various elastic demand models and the empirical case-study validations of demand elasticity. Section 3 describes the proposed method, starting with the classic four-step model method as a background, and then extending it with Lewis-Mogridge point formalization and assessment method using a novel indicator $\mu$, which can be used to compare alternative scenarios. The method is demonstrated on the case study of the $\mathrm{S} 7$ expressway bypass in Kraków in Section 4, where several induced-demand scenarios are analysed, for which the set of Lewis-Mogridge points is obtained and the $\mu$ indicator is used to compare alternative scenarios. Section 5 summarises the paper with conclusions, discussion on practical implications, and further research directions.

\section{Background}

A precise definition of generated (induced) traffic has been subject to an intensive academic debate, with studies arguing that its effects (consequences) are often hard to distinguish and cannot be observed directly. Furthermore, they tend to overlap and influence each other (e.g., the so-called rippleeffects) and are likely to have different temporal distribution and magnitude (e.g., short- vs. long-term effects) in each individual case $[7,8]$. In principle, the components of generated (induced) traffic demand, resultant from road network improvements, can be summarised as follows $[4,5,7,9,10]$ :
(1) Diverted traffic: changes in existing trip patterns, the so-called triple convergence effect [11], including spatial shifts (i.e., travel route changes), temporal shifts (i.e., changes in departure time), and modal shifts (i.e., migration between private and public transport modes).

(2) Induced traffic: new trips arising in response to improvements in quality of service (travel times, etc.) in the road network. These can be further subdivided into two main categories:

(a) Direct induced traffic: typically, the short-term response that consists of shifts in trip destinations (mainly nonsystematic trips), trip chaining patterns (e.g., longer and more complex trip patterns), and trip frequencies (increase in travel activities).

(b) Indirect induced traffic: changes in trip patterns which do not result directly from improvements in travel costs (times) but reflect the long-term increase in travel activities stemming from shifts in land-use patterns, new urban and residential developments, mobility and lifestyle changes, etc., which are in turn often facilitated by road network development $[12,13]$. Additionally, this subcategory may also encompass the "rippleeffects" in traffic flow itself such as induced traffic arising on an existing road link which was initially alleviated by a new road segment (e.g., construction of the city bypass).

Importantly, the induced traffic should not be confused with economy-based growth in travel demand, resulting from exogenous factors, which are not directly related to the transport infrastructure improvements (such as population growth), though these are often hardly separable in practice. The induced-demand phenomenon is addressed not only for urban traffic but also for public transport; for instance, for high-speed rail [14], the induced demand is included in analyses.

Appraisal of generated (induced) traffic has gained momentum as increasing amount of empirical evidence seemed to indicate that new road and highway developments, especially in urbanised areas, did not actually provide the hitherto envisaged user benefits and congestion relief, and actual traffic volumes on new road segments routinely exceeded the initially forecast values by substantial margins $[15,16]$. These phenomena were eventually analysed and concluded in more detail by researchers who noted the "selfdefeating" paradoxes of urban capacity policies [17]. Research works of $[18,19]$ that were later captured in form of the well-known Downs-Thomson hypothesis emphasise that increasing road capacity eventually leads to rising travel cost in urban networks: the increase in private transport demand imposes higher externalities costs and exacerbates road congestion, and the corresponding reduction in public transport demand implies higher unit travel costs, which need to be offset with fare increases, service frequency reductions, etc. As a consequence, the point of equilibrium 
travel yields higher cost for both transport modes, the initial objective of road expansion policy eventually "backfires" and leads to overall deterioration of travel conditions. Furthermore, research works essentially seemed to confirm this paradox and provided additional observations, such as these made by [17] that noted that in urban conditions the average car journey speed is highly likely to be determined (at the origin-destination (O-D) level) by the average "door-todoor" speed of public transport journey. It follows that any expansion of urban road capacity is unlikely to be efficient unless it is correlated with a corresponding improvement of public transport system, since in the end the distribution of travel demand flows will adapt to an equilibrium state.

This led to a formulation of an important, evidencebased paradox that is known as the Lewis-Mogridge position [20,21]; as "traffic expands to meet the available road space," i.e., benefits initially provided by newly built (or widened) roads become eventually consumed by everincreasing traffic congestion. The Lewis-Mogridge position has become ever since a "fundamental law of highway congestion" [11]. Though it does not necessarily hold true for each individual road development project, it is commonly referred to in the transport planning literature to point out that urban road capacity expansion projects often do not bring the desirable user benefits-i.e., they do not speed up the car journeys, smoothen out the traffic flow, relieve traffic jams, etc. as expected-as in longer run they will attract additional flows [22]. Notably, the traffic induction is not only related to the road network itself but also to parking policy [23], road pricing policy, and land use [24]. The induced traffic may impose additional travel costs which could not only wipe out all these benefits but also produce further externalities to deteriorate the travel conditions. Therefore, demand for road transport in congested urban areas is often a "vicious circle," hardly satisfiable by further road widening projects, urban motorway schemes, etc. Furthermore, [25] predicts that the autonomous vehicles may induce 2 to $8 \%$ road traffic up to 2035 .

Typically, the magnitude of induced-traffic phenomenon is determined by the so-called demand elasticity rate, which defines the percentage change in travel demand volume with respect to the relative change in generalised travel costs $[10,26]$. Commonly, research sources define the demand elasticity formula as either (a) the difference in traffic volumes, relative to change in car journey times or (b) the difference in vehicle-miles travelled (VMT), relative to changes in the number of lane miles of road capacity $[5,15]$. The exact rate of demand elasticity is correlated with a number of assumptions and is also likely to vary noticeably depending on a case study (which may somehow inhibit the comparability of results between individual projects); here, we just recall results from a few research works, which reflect perhaps the most common estimates of induced-traffic elasticity. Goodwin [15] defines average elasticity rates of demand volume (with respect to travel time) equal to -0.5 in short term and up to -1.0 in the long term, as supported by evidence from UK road and highway projects. Noland [27] estimates elasticity rates with respect to (introduced) lanemiles equal to 0.5 in the short run and 0.8 in the long run, with larger elasticity values in case of urban-area projects and collector roads. Schiffer et al. [28] perform a metaanalysis of previous findings and estimate the elasticity of induced vehicle-miles travelled (VMT) with respect to changes in lane-miles road capacity to be within range of $0-0.4$ in short term and $0.5-1.0$ in long term. Szarata [4] reviews results from multiple case studies, most of which yield the elasticity values (in terms of VMT changes) around ca. 0.4-0.8 in short term and ca. 0.6-1.1 in long term (yet individual studies may also yield rates outside of these ranges).

Furthermore, a common line is that higher demand elasticity should be anticipated in case of higher saturation (congestion) degree of existing road network [5]. Expanding uncongested roads will induce little or no additional traffic volumes: for rural bypass schemes along low-capacity roads, the traffic growth rate is much in line with nationwide forecasts, with barely any evidence of additionally generated traffic [29]. However, in contrary, the large-scale road (highway) schemes "fill up" more than the exogenous (i.e., nonscheme-related) factors would suggest. Empirical evidence from UK-wide postevaluation studies [15] suggested that on average road improvements induced an additional $10 \%$ of base traffic in the short term $(5-10$ years after opening) and $20 \%$ in the long term. However, the case study of M25 London Orbital Motorway revealed that the road capacity was filled up much quicker than expected. Summary of ex ante project reviews [30] shows that, under typical urban conditions, around $30 \%-50 \%$ of new road capacity is usually absorbed by induced traffic itself just within the next few years after introducing the road scheme. The growth in traffic volumes is likely to remain sustained over long term in case of large-scale road schemes that have a substantial impact in urban areas, until it reaches a selflimiting equilibrium where eventually traffic volumes would level off $[5,29]$. Typically, this would be the state where induced traffic has consumed the whole additional road capacity, essentially, an empirical confirmation of the Lewis-Mogridge position.

As noted by [5], traffic generated by new road improvements has 3 profound implications for transportation planning policies: it mitigates the congestion relief benefits of road capacity expansion programmes, imposes additional externality costs and generates congestion itself, and, finally, provides relatively smaller user benefits, since induced traffic consists mainly of vehicle trips related to nonobligatory trip purposes (e.g., leisure and shopping trips), which are less important in terms of value-of-time benefits.

Appraisal of the induced-traffic effects has recently become popular in transport planning practice [15] and resulted in a growing amount of papers that focused on evaluating user costs and benefits of road capacity expansion programmes. Mackie [31] provides a theoretical reasoning, in analogy to the principles of the classical "supply-demand law", how net changes in user costs are shaped by an elastic demand response to arising differences in generalised travel cost. For low-saturation network conditions, induced traffic may actually improve the projected net benefits, as long as it does not generate any external costs, and travel conditions 
(travel times) are not negatively affected, which could be associated with minor-scale rural road schemes, local bypasses, etc. [32]. However, and this is most often the case, as network saturation level increases, the equilibrium travel cost point shifts upwards. User benefits gained supposedly from road expansion schemes, which would be expected under the fixed-demand assumption, become actually smaller, until they may become fully consumed; beyond this point, any further changes translate into negative user costs. Litman [5] indicates that induced trips have the largest (negative) incremental travel costs, much higher than diverted trips, since they increase virtually all the externality costs. This implies that a fixed-demand approach is likely to overestimate the potential user benefits, often to a significant extent. Williams et al. [33] develop a formula for assessing the implications of demand elasticity on output performance indicators, which demonstrates that erosion in $\mathrm{CO}_{2}$ emission benefits is much more substantial than (still negative, yet more resilient) changes in car travel times, even once rates of demand elasticity as small as -0.25 are assumed. Furthermore, findings from this study reveal the contribution of different types of induced-traffic responses to overall changes in net scheme benefits: modal shifts reduce the fixed-demand benefits by ca. $8 \%-10 \%$, and other responses reduced them by further $6 \%$ to $17 \%$.

Importantly, it is often observed that although induced traffic generally comprises a minor share of total traffic volumes, volumes as small as $2 \%$ of additional traffic volumes can substantially mitigate the anticipated user benefits, forecast with fixed-demand assumptions. Coombe [16] points out that a bulk share of projected economic benefits comes from time savings and recalls sample findings from a number of UK road appraisal studies. In Norwich case study, demand elasticity rate of -0.5 resulted in an additional $2 \%-$ $3 \%$ number of trips but led to reductions in the fixeddemand economic benefits of more than $20 \%$. Similarly, for the city of Belfast, an induced-traffic rate of just $2 \%$ substantially reduces the anticipated reductions in vehicle-hours travelled (which otherwise decrease by $5 \%$ in the fixeddemand model). Even more interestingly, a study of crucial urban road development scheme in the already congested West London area indicated that a $1 \%$ induced-traffic rate would diminish the fixed-demand economic benefits by $30 \%$. Ness et al. [34] provide further evidence from Denmark road expansion projects, noting that travel time savings in CBA analysis of motorway projects may comprise more than $80 \%$ of total benefits.

Regardless of size and scope of the road investment project, induced-traffic effects tend to decrease anyway with the size of analysis area [28]. Changes due to induced traffic from smaller-scale or local road improvement schemes may not be thus initially captured on an aggregate, city-wide scale but could alter substantially the network performance within the direct impact area. Therefore, the effects of induced travel need not be necessarily pronounced in large-scale road and highway projects only. Szarata [4] provides simulation results for a case study of upgrading an existing roundabout to a 3-level interchange with free-flow links in the city of
Kraków (Poland). When accounting for the extra 3\% induced-traffic volume, this implies a shift from a reduction of 200 vehicle-hours travelled (with a fixed-demand model of average PM peak hour) to an increase of 200 vehicle-hours travelled (induced-demand model) instead, compared to the "do-nothing" scenario, though these local changes diminish on the network-wide scale.

Additionally, actual changes in net road scheme benefits (costs) often vary with respect to the analysis timeframe, being strictly dependent on the demand sensitivity rate. Initial relief provided by road and highway schemes may last for either a few months or a few years, when externality costs imposed by induced traffic still have not outweighed the benefits provided by the expanded road capacity; extending the analysis time horizon can reveal the overall impact of the road scheme and capture the "turning-point" of Lewis-Mogridge paradox when the net scheme contribution turns negative, as demonstrated on a theoretical model by [35]. Estimates provided by [34] for a mildly congested motorway project demonstrate that, on a longer time horizon, the CBA results may have been essentially different. Williams and Yamashita [35] demonstrate in an estimate for the Cardiff city case study that, contrary to minor shifts in net benefits in shortterm perspective, over a 25 -year evaluation period, the inclusion of demand elasticity response equal to -0.25 reveals a total user-benefit overestimation rate in fixed-demand approach of ca. $28 \%$; for demand elasticity equal to -1.0 , this rises up to $50 \%$. Litman [5] further emphasises these implications for multimodal project appraisal, which he supports with a numerical example; once included in the CBA analysis, the aggregate long-term costs due to induced traffic can essentially shift the balance of project evaluation in favour of public transport solution, yielding the road scheme with a negative outcome.

Although in Section 1 we listed a broad number of research works where induced traffic was quantified and numerous models were proposed, practical estimates of induced traffic often differ depending on individual case study, local conditions, exact definition of induced demand, etc. Thus, forecasting induced demand is methodologically cumbersome, as direct evidence is not available during the appraisal stage (ex ante). The input data can be either declared by network users (stated-preference studies), assumed to be analogous to similar cases (based on evidence from previous road schemes), or just observed expost (after implementation of road scheme). Statistically sound and solid estimates of induced traffic are typically unavailable or doubtful. For this reason, assumptions based on fixed traffic demand are made in many appraisal studies. This raises a practical problem when the project can be assessed either based on an unrealistic assumption of fixed travel demand or by utilising arbitrary assumptions of induced (variable) travel demand, none of which seems satisfactory. That is why we propose a different assessment method below. Such approach, detailed in the subsequent section, is to our knowledge the first method that does not require arbitrary assumptions, allows to compare alternative scenarios and still explicitly considers induced traffic. 


\section{Method}

In this, main part of this paper, we propose an alternative method complementing approaches to modelling the effects of induced traffic. We start with the formal introduction of the four-step model, which comprises the most common, fundamental travel demand model for transportation planning practice.

As our objective is to observe the performance of road traffic network, we measure it by means of the following three output indicators: total distance travelled (vehiclekilometres), total trip duration (vehicle-hours), and their ratio (average network speed). To obtain those values, we use the User Equilibrium (UE) assignment. The UE is a commonly applied assignment method, according to which drivers iteratively update their travel decisions in order to minimize their travel costs (times) and avoid traffic congestion [36]. User Equilibrium can be generically expressed as

$$
\mathbf{q}=\mathrm{UE}(\mathbf{s}, \mathbf{d}),
$$

where the travel demand $\mathbf{d}$ is assigned onto the traffic supply (road network) $\mathbf{s}$ to produce the output network traffic flows q. We use the bold (vector) notation to denote the global (network-wide) values, i.e., $\mathbf{q}=\left\{q_{a}: a \in A\right\}$. The supply (traffic network) is defined as a directed, connected graph $\mathbf{s}=(N, A)$ of nodes $n \in N$ and $\operatorname{arcs} a \in A$. The nodes are by default nonparametrized, while arcs are parametrized with length $l_{a}$, free-flow speed $v_{a}^{0}$, capacity $q_{a}^{\max }$, and travel time function $t_{a}\left(q_{a}\right)=\left(q_{a}, q_{a}^{\max }, v_{a}^{0}\right)$. Results of the assignment procedure are arc traffic flows $q_{a}$. We estimate travel time with a macroscopic volume-delay function (VDF) computed from the saturation rate (volume-to-capacity ratio); here, we use the standard Bureau of Public Roads (BPR) function:

$$
t_{a}=\frac{l_{a}}{v_{a}^{0}} \cdot\left(1+a\left(\frac{q_{a}}{q_{a}^{\max }}\right)^{b}\right),
$$

where $a$ and $b$ are parameters. For the sake of simplicity, we use such elementary travel time function (detailed elaboration on VDF functions can be found in [37]). The reason to use the abovementioned static macroscopic traffic flow model is the fact that it is commonly used in strategic planning and project appraisal and there are no strict recommendations to use more realistic models, such as the first-order macroscopic model of [38] or microscopic agentbased simulators [39] that provide a more detailed picture of queues, spillback, and congestion-related phenomena. Nonetheless, with the above travel time formulas, we can reproduce propagation of the vehicles through the road network with limited (constrained) capacity where congestion would eventually occur.

Trip demand is defined between zones $Z \subseteq N$ with $d_{\text {od }}$, i.e., the demand between origin $o$ and destination $d$, usually defined for a peak hour. Demand is typically obtained from the four-step model, where trips are computed in the following sequence: trip generation, time-of-day choice, trip distribution, and mode choice. The final step is when the demand is supplied in UE traffic assignment (equation (1)), which reproduces drivers' route-choice behaviour, i.e., how they subjectively choose optimal paths to reach their destinations. Each driver aims to minimize his own travel times (costs) by selecting the path in the network $\mathbf{s}$ yielding minimal travel costs. Travel costs are usually composed of absolute (physical) travel times (equation (2)) and subjective (perceived) attributes like comfort, reliability, past experience, etc. Notably, since road network capacity is limited and insufficient, especially during peak-demand periods, travel times on the shortest routes increase (equation (2)) and drivers seek for more efficient paths. Such adaptive procedure is well represented within the User Equilibrium model (equation (1)), which is broadly defined in the literature; for recent review, we refer to [40].

3.1. Four-Step Demand Model (FSM). We denote the travel demand model as FSM (four-step model) and generically express it with

$$
\mathbf{d}=\operatorname{FSM}(\boldsymbol{\alpha}, \mathbf{x}),
$$

where trip demand $\mathbf{d}$ is obtained from a set of parameters $\boldsymbol{\alpha}$ and input variables $\mathbf{x}$. This general formulation is further decomposed to four steps according to the following steps.

In the trip generation stage, $D_{o, p}$, expected daily number of trips of purpose $p$ departing from origin $o$ is estimated. Trip purposes comprise typically both Home-Based trips (Home-Work-Home, Home-Education-Home, and HomeOther-Home) and Nonhome-Based trips [41]. Usually, the linear regression is estimated using results from the revealed-preference survey with the explanatory variables $x$ being demographic data (population), number of work and school places, land-use spatial data (total area of, e.g., commercial, industrial, and leisure facilities), etc., weighted with estimated parameters $\alpha_{g}$. For the purposes of our case study, we use the demand model formulated as in the 2013 Kraków Comprehensive Travel Study [42]. We generically express the trip generation from zone $o$ in trip purpose $p$ as

$$
D_{o, p}=\alpha_{g_{1}} \cdot x_{1}+\alpha_{g_{2}} \cdot x_{2}+\cdots+\alpha_{g_{n}} \cdot x_{n} .
$$

The daily number of generated trips estimated with equation (4) is then distributed over the day. In the time-ofday choice model, the number of trips during a respective part of the day (usually AM and/or PM peak hour) is determined using an hourly share $\alpha_{h, p}$ estimated for each trip purpose from the survey data:

$$
D_{o, p, h}=\alpha_{h, p} \cdot D_{o, p} .
$$

In the third step, the origin demand is then assigned (distributed) onto trip destinations according to the trip distribution model. Classically, the gravity-based models are used with distance-decay parameters estimated from the survey data. Since there is no closed-form formulation of the gravity model [43], we denote it as TD and define it generically as follows:

$$
D_{o, d, p, h}=\operatorname{TD}\left(D_{o, p, h}, d, c_{o d}\right),
$$

where number of trips between origin and destination is computed with respect to the origin demand volume $D$, 
attractiveness rate of destination $d$, and distance-decay function $c_{o d}$. Usually the distance-decay function is expressed as a PDF (probability density function) of exponential or log-normal distribution shape.

Once trip matrices have been computed, the modechoice model is applied in the next step to estimate modal shares. Usually, the considered mode alternatives are car, public transport, walk, and bike. Here, we are interested only in the share of car trips $s_{o, d, p, h, m}$ which we express with a generic multinomial logit (MNL) model:

$$
s_{o, d, p, h, m}=\left(\frac{\exp \left(U_{m}\right)}{\sum_{m^{\prime} \in M^{\prime}} \exp \left(U_{m^{\prime}}\right)}\right),
$$

where $U_{m}$ is the utility of an alternative $m$ from the available choice-set of alternatives $M$. The share is then used to extract the number of trips conducted by car (mode $m$ ) from origin $o$ to destination $d$ during peak hour $h$ for trip purpose $m$ :

$$
d_{o, d}=\sum_{p \in P} s_{o, d, p, h, m} \cdot D_{o, d, p, h},
$$

which is the final output of the demand model and becomes an input of assignment procedure (equation (1)) where it is assigned on the supply model (road network) s to obtain output network flows $\mathbf{q}$.

3.2. Impact Assessment of Road Network Improvements with FSM. Traffic flows in the road network $\mathbf{q}$ (resulting from the assignment equation (1)) can be used to estimate the network performance. Commonly, in the multicriteria analysis, a number of various cost definitions are used, and network costs are in fact a vector of various perspectives of costs. Here, we measure the network costs by means of following performance indicators: total vehicle kilometres $C_{l}$, total vehicle hours $C_{t}$, and their ratio-average speed $C_{v}$ :

$$
\begin{aligned}
& C_{l}(\mathbf{q})=\sum_{a \in A} q_{a} \cdot l_{a}, \\
& C_{t}(\mathbf{q})=\sum_{a \in A} q_{a} \cdot t_{a}, \\
& C_{v}(\mathbf{q})=\left(\frac{C_{l}(\mathbf{q})}{C_{t}(\mathbf{q})}\right),
\end{aligned}
$$

with main emphasis on total travel time $C_{t}$, which is both the most meaningful parameter for car drivers and, at the same time, the objective in the UE assignment. Within the abovementioned framework, one can investigate the impact of changes in the road network supply s on travel costs. The network improvement $\mathbf{s}^{+}$scenario may refer to either construction of a new road link (e.g., new bypass or urban arterial road) or an upgrade to existing road infrastructure (e.g., road widening scheme and rebuilding intersections to grade-separated junctions with free-flow links). It can also comprise a combination of several such schemes. The designed improvements are expected to bring relevant improvements in system performance by reducing the travel times $C_{t}$ along existing routes, which can now accommodate more traffic within an acceptable travel time (equation (2)), or by providing new opportunities to reach the destination along a new path with lower travel time. We denote the supply improvement by $\mathbf{s} \longrightarrow \mathbf{s}^{+}$when a new road-network graph extending the existing one is created. The graph can be modified by changing the arc parameters (e.g., higher capacity of existing arcs) or creating new arcs in the topology (new arteries).

In general, the impact of supply changes on network performance can be estimated assuming the demand is either fixed or elastic. In the baseline method, which is common in the state-of-the-practice appraisal studies, the impact of road network improvement is assessed only at the assignment level (e.g., 1), with an implicit assumption that travel demand $\mathbf{d}$ is fixed. In such case, travel demand (which remains unchanged) is distributed to the new supply graph with lower travel cost. In this case, the solution is obtained simply with

$$
\mathbf{q}^{+}=\mathrm{UE}\left(\mathbf{s}^{+}, \mathbf{d}\right)
$$

where the fixed-demand trips $\mathbf{d}$ are supplied to a new traffic network $\mathbf{s}^{+}$, yielding new travel costs which we hope to be lower than the initial ones (at least in terms of travel time):

$$
C_{t}\left(\mathbf{q}^{+}=\mathrm{UE}\left(\mathbf{s}^{+}, \mathbf{d}\right)\right) \leq C_{t}(\mathbf{q}=\mathrm{UE}(\mathbf{s}, \mathbf{d})) .
$$

This allows to express the benefits $B\left(\mathbf{s}^{+}\right)$of network improvement $\mathbf{s} \longrightarrow \mathbf{s}^{+}$in terms of total cost reduction. Most importantly, in terms of total travel times (equation (14)) and also in terms of total trip distance reduction (equation (15)) and vehicle speed increase (equation (16)) (which is maximized, opposite to travel distance and time which are minimized):

$$
\begin{gathered}
B_{t}\left(\mathbf{s}^{+}\right)=C_{t}(\mathbf{q})-C_{t}\left(\mathbf{q}^{+}\right), \\
B_{l}\left(\mathbf{s}^{+}\right)=C_{l}(\mathbf{q})-C_{l}\left(\mathbf{q}^{+}\right), \\
B_{v}\left(\mathbf{s}^{+}\right)=C_{v}\left(\mathbf{q}^{+}\right)-C_{v}(\mathbf{q}) .
\end{gathered}
$$

Road network improvements are usually assessed based on the abovementioned benefits or by comparing the costs before ("do-nothing" scenario) $\mathbf{C}(\mathbf{q})$ and after (improvement scenario) $\mathbf{C}\left(\mathbf{q}^{+}\right)$. This allows to compare various scenarios and rank them to select the optimal one, as well as compose multicriteria indicators where various types of costs can be analysed.

The fixed-demand assumption, as we discussed in Section 1, is doubtful for many researchers and practitioners, since it neglects the crucial phenomenon of induced traffic demand. Thus, it is advocated to extend this approach by assuming that travel demand is variable and sensitive to supply (network) improvements as well as changes in quality of service (e.g., travel times). In such case, we can express the demand induction as a function of supply improvements:

$$
\mathbf{d}^{+}=f\left(\mathbf{s}^{+}\right) .
$$


If so, the demand expressed with FSM (equation (3)) changes as well, which we can formally express as a change of parameters and/or variables of the FSM:

$$
\mathbf{d}^{+}=\operatorname{FSM}\left(\boldsymbol{a}^{+}, \mathbf{x}^{+}\right),
$$

where $\boldsymbol{\alpha}^{+}$denotes changes in the demand model parameters and $\mathbf{x}^{+}$denotes changes in explanatory variables. This plays an essentially opposite role to network improvement in the assignment (equation (1)). Whereas network improvement in general should lead to cost reduction $\left(\left(\partial C_{t} / \partial \mathbf{s}\right)<0\right)$, the demand growth leads concurrently to cost increase $\left(\left(\partial C_{t} / \partial \mathbf{q}\right)>0\right)$. This raises a complex problem; when the road improvement might bring benefit on one side, yet at the same time these can be mitigated by increased traffic demand.Notably, increased demand interdependently relates to supply changes through (equation (17)). Traffic demand can even increase up to the point where the benefits become null, like in the Lewis-Mogridge position, which is in practice not an uncommon phenomenon, especially in metropolitan areas. This can be due to one or more of following FSM changes:

(1) Changes in explanatory variables, e.g., population and workplace increase due to road investment, formally expressed through the $\mathbf{x} \longrightarrow \mathbf{x}^{+}$change in equation (4)

(2) Changes in trip generation rates; for example, trip frequency (average number of trips per person) becomes higher for some trip purposes $m$, either on a global (i.e., within the whole city) or local scale (i.e., in selected zones within the direct impact area of road scheme), formally expressed as the $\boldsymbol{\alpha}_{\mathrm{G}} \longrightarrow \boldsymbol{\alpha}_{\mathrm{G}+}$ change in equation (4)

(3) Changes in time-of-day choices, e.g., more trips are again executed during peak hour due to relieved congestion (the so-called peak narrowing), formally expressed as the $\boldsymbol{a}_{\mathbf{h}} \longrightarrow \boldsymbol{a}_{\mathbf{h}+}$ change in equation (5)

(4) Changes in destination choice, e.g., more trips are executed to remote destinations due to lower travel costs, formally expressed as the $\mathbf{c} \longrightarrow \mathbf{c}^{+}$change in equation (6)

(5) Mode shifts towards car due to higher car utility $U_{m}$ in the mode choice model (equation (7)), leading to higher share $s$ of trips executed with a car, formally expressed as the $\mathbf{U}_{\text {car }} \longrightarrow \mathbf{U}_{\text {car }}^{+}$change

(6) The nonrational perception of a new investment, i.e., increased riding comfort and/or subjective underestimation of travel times along the new (improved) road segment $t_{a} \longrightarrow t_{a}^{+}$

Unfortunately, determining the abovementioned changes is nontrivial and usually requires arbitrary assumptions, that is why we propose an alternative approach below.

3.3. Lewis-Mogridge Points of FSM Model. Instead of asking how would network conditions change depending on certain (a priori) demand assumptions, we ask what is the threshold of induced demand under which the benefits are no longer positive. Specifically, we hypothesize that the Lewis-Mogridge position (detailed in Section 1) holds true in simulation analysis. If so, net improvement benefits are null $\left(B_{t}\left(\mathbf{s}^{+}\right)=0\right)$ due to postimprovement traffic induction. Thus, the reformulated question is the following: what adjustments in the demand model will lead to a null benefitcost balance as a result of analysed road improvement? We denote such demand with $\mathbf{d}^{*}$, the so-called Lewis-Mogridge point, and formalize it with

$$
\mathbf{d}^{*}: C_{t}\left(\mathrm{UE}\left(\mathbf{s}^{+}, \mathbf{d}^{*}\right)-C_{t}(\mathrm{UE}(\mathbf{s}, \mathbf{d})=0 .\right.
$$

From the list of possible demand changes in Section 2, one can see that there are several interdependent parameters and variables that could change in response to supply (network) modifications. Each of them might lead to null benefit-cost balance at some level, and the problem of finding Lewis-Mogridge points is underdetermined with many possible solutions. Since the number of parameters and variables of FSM is high, this also results in a large and complex solution space where the Lewis-Mogridge points can be found. Instead of exploring this space, we try to expose the partial derivatives of travel cost over a single variable. We incrementally increase the variable until reaching the Lewis-Mogridge point $\mathbf{d}^{*}$. This simplest method of finding the Lewis-Mogridge points (single-variable analysis) allows to estimate partial derivatives and understand the benefits sensitivity subject to changes in respective explanatory variables or parameters. Such analysis can be treated as a way to explore the multidimensional gradient in this complex space $\left(\partial C_{t} / \partial \mathbf{d}\right)$. It is further used to propose compound scenarios for which more plausible Lewis-Mogridge points are found, as a combination of smaller-scale changes in multiple parameters.

Notably, the Lewis-Mogridge points (equation (19)) can be used to propose a new benefit measure. We propose to formulate it around the two variables: one is the initial benefit (equation (12)) and the other is the magnitude of induced demand needed to reach the Lewis-Mogridge point. They form the kind of momentum where the mass is the initial benefit (obtained with (equation (12)) and the distance is magnitude of demand changes:

$$
\mu_{\mathbf{s}^{+}}=B_{t}\left(\mathbf{s}^{+}\right) \cdot\left\|\mathbf{d}, \mathbf{d}^{*}\right\| \text {. }
$$

The distance reflects how big the demand induction has to be to reach the Lewis-Mogridge point (and diminish the benefits). The closer it is, the smaller the resilience of scheme-provided network benefits is. We propose to express the distance between original and induced demand by means of the relative growth in the number of trips resulting from the demand model:

$$
\left\|\mathbf{d}, \mathbf{d}^{*}\right\|=\left(\frac{\left(\sum_{o, d \in Z} q_{o, d}^{+}-\sum_{o, d \in Z} q_{o, d}\right)}{\sum_{o, d \in Z} q_{o, d}}\right) .
$$

Using the distance measure (equation (21)), we can rank the Lewis-Mogridge points found during the search procedure and select the most probable ones. The probability of induced demand changes is hard to estimate, and we simply 
assume that it is inversely proportional to the trip distance (equation (21)), i.e., the smaller the number of trips to be induced the higher the likelihood of traffic demand induction. Consequently, from set of found Lewis-Mogridge points $\mathbf{D}^{*}$, we select the one being the closest to original demand and treat it as the most probable:

$$
\mathbf{d}^{* \min }=\underset{\mathbf{d}^{*} \in \mathbf{D}^{*}}{\operatorname{argmin}}\left\|\mathbf{d}, \mathbf{d}^{*}\right\| .
$$

We propose to use $\mathbf{d}^{* \min }$ as the reference and use it in equation (20) for further road network assessment, the main contribution of this paper:

$$
\mu_{\mathbf{s}^{+}}=B_{t}\left(\mathbf{s}^{+}\right) \cdot\left\|\mathbf{d}, \mathbf{d}^{* \min }\right\| .
$$

Consequently, we can now estimate $\mu$ for each analysed network improvement with equation (20), which will cover both the fixed-demand initial benefits and number of trips needed to consume it. This measure can be used to compare alternative network improvements and select the optimal one. Significantly, two alternative improvements of similar benefits can be compared and tested against the induced demand. As we demonstrate in the result of the case study, $\mu$ allows to distinguish from two similar improvements the one which is more resilient to induced demand, i.e., the one which allows more induced demand to remain beneficial or (alternatively) which is less likely to be consumed by induced demand.

3.4. Local Impact of Global Demand Changes. The above analysis relies on global values, and both the cost (equation (9)) and benefits (equation (14)) are aggregated for the whole network. However, induced traffic is not necessarily equally distributed across the network. Some vulnerable network arcs may be significantly more affected by demand changes than others. To this end, similar to the abovementioned global consequences of traffic inductions, we also look for "local" Lewis-Mogridge points, i.e., such demand growth where the speed $v_{a}$ drops back to its initial level. This is especially important in case the improvement is aimed to relieve congestion at some specific network element (e.g., bridge), and it should be properly understood when the induced traffic would possibly reduce the speed back to its initial (preimprovement) values locally and not necessarily at the network level.

In results reported below, we observed not only aggregate network parameters but also some selected individual network arcs for separate analysis. Since the analysed investment comprises a new (major) river crossing (the S7 expressway project), we also observed the performance (in terms of travel times estimated with equation (1)) of alternative bridge crossings.

\section{Results}

To illustrate the method, we analysed a major investment scheme in the Kraków road network. The eastern section of the city bypasses a three-lane dual-carriageway expressway with speed limit of $120 \mathrm{~km} / \mathrm{h}$ including a new bridge crossing over the Vistula river which was opened in the middle of 2017. It allows through traffic bypassing the congested innercity road network and creates a new connection between the northeastern and southeastern parts of the city as illustrated in Figure 1. We first found several LM points of this investment by modifying demand model parameters and variables to reproduce the induced demand. Finally, we compared alternative investments of similar initial benefits with the proposed $\mu$ indicator, which allowed to identify the investment that is more resilient to induced demand.

Simulations were conducted using strategic transport planning model developed for the city of Kraków, Poland. We used static user equilibrium assignment and detailed network graph with specific, link-type-based travel time functions (equation (2)) estimated from the field data. Demand model was estimated according to the results of 2013 Kraków Comprehensive Travel Study [42]. We analysed morning peak hour (7 AM to $8 \mathrm{AM}$ ) traffic flows calibrated to match the observed traffic flows. The demand model included in Krakow simulation model was developed in accordance with FSM specifications introduced above and meets the official requirements imposed for the project appraisal. Simulation output, which was used for further analysis, comprised network traffic flows $\mathbf{q}=\left\{q_{a}: a \in A\right\}$ and travel times $t_{a}$, from which travel costs $C$ could be computed with equation (9). The open structure of the demand model allowed to recompute the FSM (equation (3)) for any set of parameters and variables.

We run several scenarios in which we investigate the cost sensitivity subject to selected parameters changes. Travel costs changes are traced against the following demand model variables:

(a) Total population growth

(b) Population growth in the analysis corridor (i.e., direct impact area)

(c) Trip generation growth

(d) Peak-hour share growth

(e) Distance-decay decrease (in trip distribution function)

(f) Private car relative utility increase

(g) Increase in perceived attractiveness of the analysed road segment

For each of them, we increase the respective demand variable ca. 5 to 10 times by the same incremental step in order to find the Lewis-Mogridge (L-M) point and to expose the cost sensitivity.

Results are presented in terms of travel costs (total travel times $C_{t}$ ) expressed as a function of varying demand, traced through changes to respective parameter $\left(\boldsymbol{a}^{+}\right)$or variable $\left(\mathbf{x}^{+}\right)$. For scenarios where trip volumes growth can be traced directly, we calculate the distance (equation (21)) and the corresponding $\mu$ value (equation (20)), which we use to compare the results with alternative scenarios.

Additionally, to complement the picture, apart from showing the global (network-wide) results, we also report the direct impact on three alternative river crossings. Since 


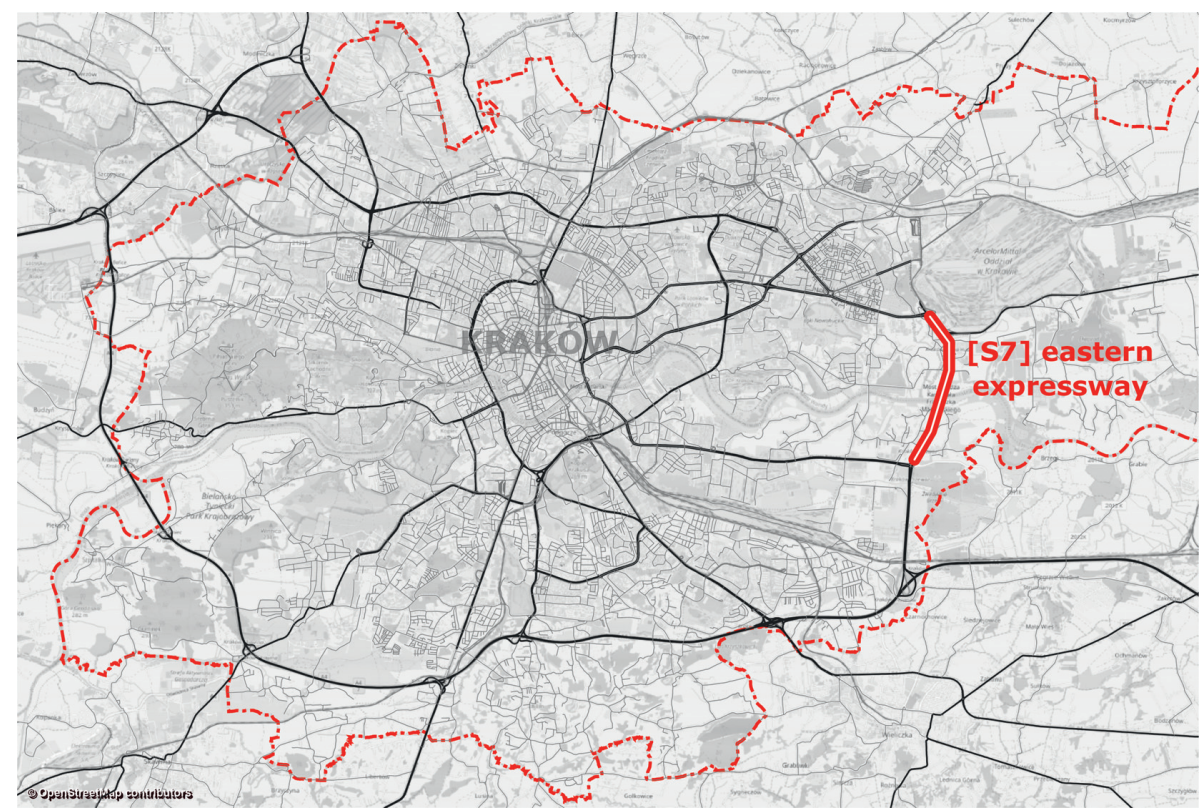

FIGURE 1: Analysed road segment of the expressway S7 (marked red) forming eastern bypass of the Krakow city, with a new bridge crossing over Vistula river (@ http://www.OpenStreetMap.org).

the analysed road scheme includes a new major river crossing, we are interested in traffic speed changes on three important alternative bridges in the central part of Krakow: the Nowohucki, Kotlarski, and Debnicki bridges. We investigate how the traffic speed relative to the fixed-demand scenario decreases until it reaches the value prior to the investment, when the so-called local L-M point is reached.

4.1. Fixed Demand. We start with modifying the baseline network (supply model) graph $\mathbf{s} \longrightarrow \mathbf{s}^{+}$where we introduce the new road link (the S7 expressway). A total of ca. 10 kilometres of new arcs of capacity $3200 \mathrm{veh} / \mathrm{lane} / \mathrm{hr}$ and freeflow speed of $120 \mathrm{~km} / \mathrm{h}$ were added to the network graph. First, we assume that traffic demand is fixed and flows are obtained according to the $\mathrm{UE}\left(\mathbf{s}^{+}, \mathbf{d}\right)$ model (equation (1)). As expected, new efficient paths were found in the graph, which yielded lower travel costs, as illustrated in Figure 2 and in Table 1. The benefits obtained under the assumption of fixed demand are thus significant: a difference of over 2000 vehicle-kilometres, almost 500 vehicle-hours, and an average speed increase of almost $1.0 \mathrm{~km} / \mathrm{h}$. These correspond to a $2 \%$ reduction rate in vehicle-hours and the average speed increase of $2 \%$. In terms of local impact of the S7 scheme, average traffic speed on the nearest alternative bridge (Nowohucki) rose from $39 \mathrm{~km} / \mathrm{h}$ to over $43 \mathrm{~km} / \mathrm{h}$; on the more distant Kotlarski bridge, the speed increase was lower ( 38.6 to $39.0 \mathrm{~km} / \mathrm{h}$ ), while on the inner-city and the most congested Debnicki bridge, traffic congestion did not improve at all (remaining at a stable speed of barely $11 \mathrm{~km} / \mathrm{h}$ ).

In further scenarios, we assume that supply changes $\mathbf{s} \longrightarrow \mathbf{s}^{+}$will induce changes in travel demand volumes $\mathbf{d} \longrightarrow \mathbf{d}^{+}$. The effect will not be simply obtained from equation (1), but we will estimate the new demand model (equation (17)) for given assumptions in changes of parameters and use it to compute the new user equilibrium $\mathrm{UE}\left(\mathbf{s}^{+}, \mathbf{d}^{+}\right)$(equation (12)).

4.2. Total Population Growth. We start with the assumption that road improvement benefits can be consumed due to the general population growth. We simulated a uniformly distributed relative population growth rate for all traffic zones within Krakow. Since population is a principal factor shaping the mobility patterns and their costs, we presume it would have significant impact on road network benefits. Indeed, total travel costs turned out to be strongly related to the population in the modelled area. We gradually increased the population up to an extra 10\% (1.1 multiplier) and found the Lewis-Mogridge point at $\mathbf{x}_{\mathbf{p}} \longrightarrow 1.028 \cdot \mathbf{x}_{\mathbf{p}}$. This implies that the initial benefits of the S7 expressway (reported in Table 1) would be consumed when total population would grow by ca. $2.8 \%$ (in comparison, total accumulated growth over last 20 years was ca. 2.4\%). Results are presented in Figure 3 where total travel costs are expressed as a function of population growth, with two horizontal lines representing total costs under fixed-demand assumption (lower line) and total costs without the improvement, i.e., initial ("donothing") scenario (upper line). The Lewis-Mogridge (L-M) point is found when total travel costs intersect with the initial-scenario horizontal line (marked with a square). Since the number of trips in demand model is roughly proportional to the population, the global L-M point is reached when the distance $\left\|\mathbf{d}, \mathbf{d}^{*}\right\|$ (equation (21)) expressed in terms of the number of trips is $2.8 \%$, which yields the $\mu$ value computed with equation (20) of $2.8 \% \cdot 459=7.25$ (veh. $\mathrm{km}$ ).

Although the $2.8 \%$ population growth consumes $100 \%$ of benefits of the road network improvement, we also take a closer look at the output traffic performance of alternative 


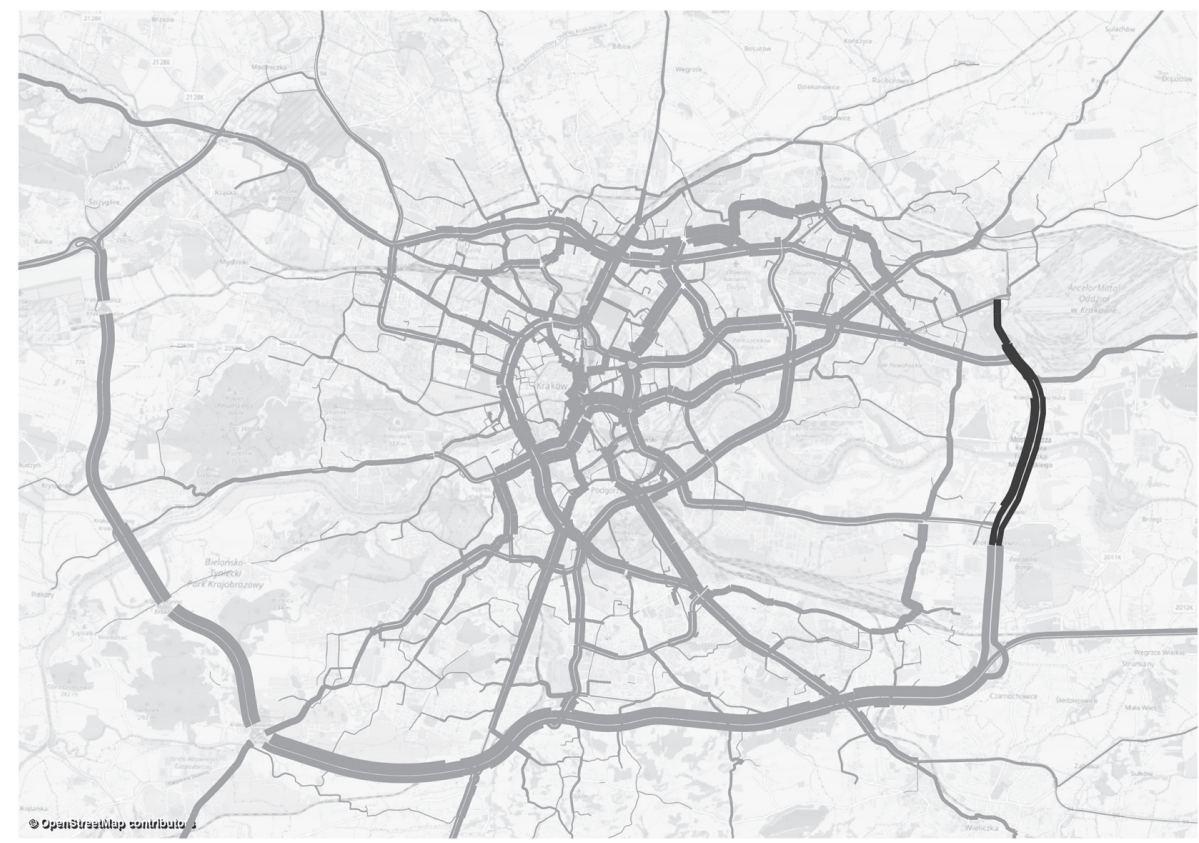

Figure 2: Fixed-demand traffic flows after eastern expressway (S7) in Krakow is opened (new arcs marked with solid black; bars denote morning peak flow).

TABle 1: Fixed-demand benefits of the road network improvement scheme.

\begin{tabular}{lcccc}
\hline Cost & $C$ & $C_{d}(\mathrm{veh}-\mathrm{km})$ & $C_{t}(\mathrm{veh}-\mathrm{h})$ & $C_{v}(\mathrm{~km} / \mathrm{h})$ \\
\hline Initial ("do-nothing”) & $C(\mathbf{q}=\mathrm{UE}(\mathbf{s}, \mathbf{d}))$ & 1013987 & 22123 & 45.833 \\
After improvement & $C\left(\mathbf{q}^{+}=\mathrm{UE}\left(\mathbf{s}^{+}, \mathbf{d}\right)\right)$ & 1011961 & 21664 & 46.711 \\
\hline Benefit & $B\left(\mathbf{s}^{+}\right)$ & 2026 & 459 & 0.878 \\
Relative & $(B / C)$ & $0.2 \%$ & $2.0 \%$ & $1.92 \%$ \\
\hline
\end{tabular}

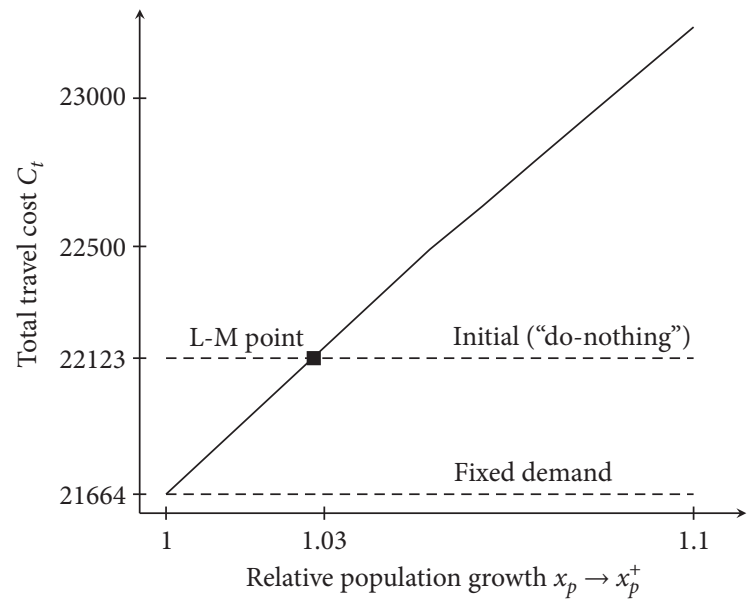

Figure 3: Travel costs $C_{t}$ against population growth.

river crossings. We aim to understand when the speed at alternative bridges drops back to the prior-investment values. Results are presented in Figure 4, where three analysed bridges are marked with different line styles and squares denote when the speed drops to the initial-scenario level (before the improvement scheme), i.e., the local L-M points for respective bridges (labelled on the left side). Speed at the Kotlarski bridge goes down to the initial-scenario

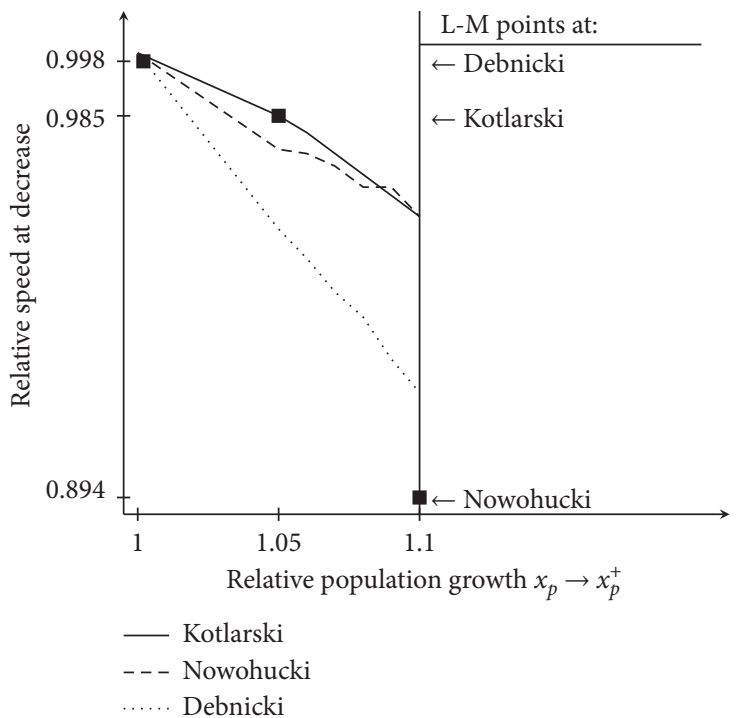

FIGURE 4: Relative speed decrease at alternative bridges against population growth.

value at ca. $5 \%$ population growth; at the Nowohucki bridge it still remains at higher rates even up to the maximum $10 \%$ population growth. Interestingly, traffic conditions at the inner-city Debnicki bridge do not improve significantly once 
S7 road is opened, but what is more important is the fact that speed drops down immediately once population rate is growing up, regardless of the introduced S7 scheme, and drops way below initial-scenario value in the $10 \%$ population growth scenario.

4.3. Impact Corridor Population Growth. Now we restrict the population growth to the direct impact corridor, i.e., traffic zones directly affected by improvements in the level of service. This could occur as, for example, improved road infrastructure could further catalyse the urban development of neighbouring areas [4]. The impact area was delimited by using the average travel time reduction criterion (with a $5 \%$ threshold). We run this experiment analogically to the previous one, yet with population growth restricted to those traffic zones only for which travel times were reduced. Obviously, compared to the previous case, in this scenario, a higher relative population growth is needed to reach the global L-M point. The $17 \%$ population growth in the impact corridor would be needed to erode all the S7 scheme benefits in Figure 5. We observe that impact of such changes is local, since alternative bridges are less affected than previously as presented in Figure 6. In terms of achieving local L-M points, a $34 \%$ population growth in corridor would be needed until traffic speed at the Kotlarski bridge would reach the initialscenario value. In turn, traffic speed at the most congested Debnicki bridge is less sensitive to the impact corridor population growth than previously, as are speeds for other alternative bridges in general; therefore, if population growth is limited to the directly affected area only, the negative impact of induced demand could be somehow alleviated.

Notably, the L-M point obtained by increasing population rates in the impact corridor yields lower growth in total number of trips (equation (21)). Since ca. 12\% of city population lives within the impact corridor, and its L-M point is found for the $17 \%$ growth rate, this translates into $2.0 \%$ relative growth in total number of trips. Consequently, $\mu$ becomes $5.28(\mathrm{veh} \cdot \mathrm{km})$. Yet, since this scenario relies on investment dependent (impact corridor) and arbitrary (5\% threshold) assumption, we will not use it for further scenario comparison.

4.4. Trip Generation Growth. In this scenario, assuming a constant population rate, we investigate the effects of an increased mobility rate. We assume that since travel costs are lower due to new investment, some people will decide to travel more frequently [5]. We represent it with the $\alpha_{g} \longrightarrow \alpha_{g^{+}}$increase.

Results are analogous to the previous (population growth) scenarios, yet their practical interpretation may be different. Although in densely populated cities it might be eventually unlikely that the population will grow even further, it is conceivable that mobility rates may grow once travel costs are reduced due to improved traffic conditions. On contrary, in sparsely populated areas, a double increase in population might be probable (especially for lower initial population rates) but a double increase in the mobility rate

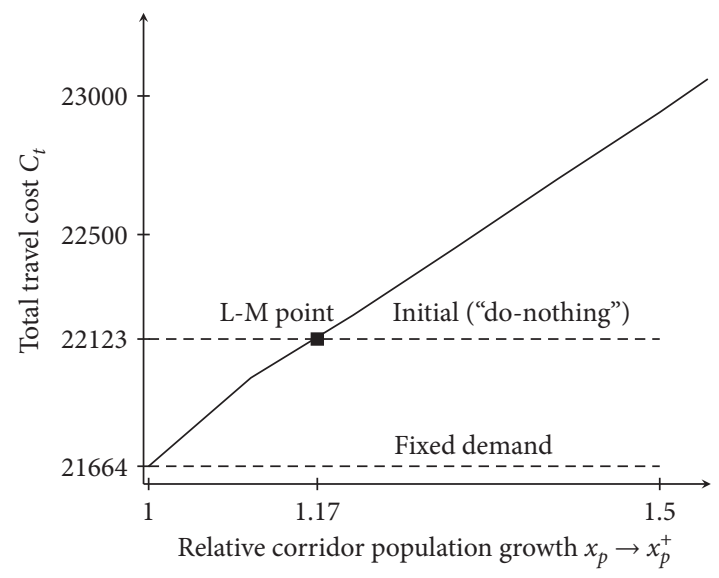

Figure 5: Travel costs $C_{t}$ against corridor population growth.

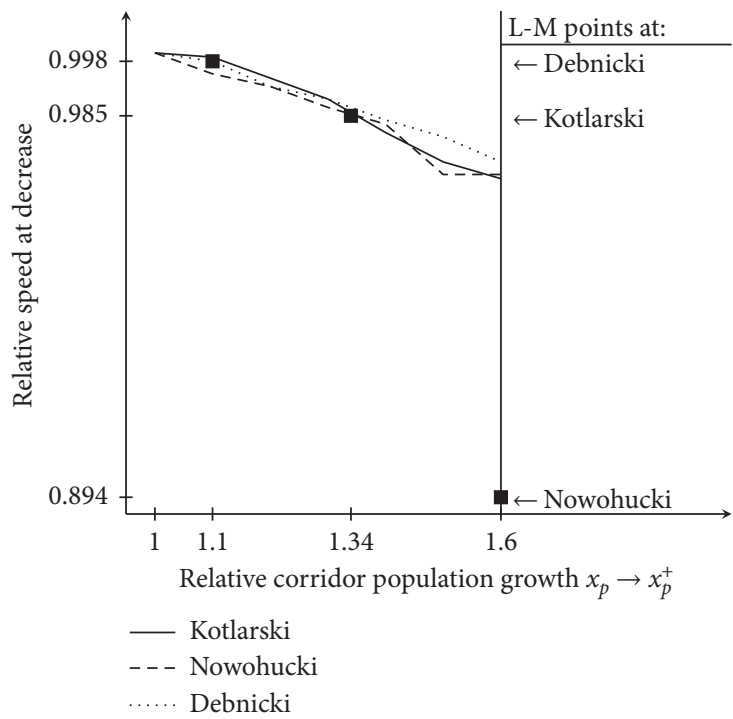

Figure 6: Relative speed decrease at alternative bridges against corridor population growth.

seems hardly possible. Results are depicted in Figures 7 and 8 . The $2.8 \%$ global mobility increase rate yields travel costs equal to the initial-scenario ones.

In this scenario, we tested a wider range of trip generation increase, which allowed to expose the linear trend up to $20 \%$ of extra mobility growth The local L-M point is still not reached on the Nowohucki bridge, where traffic speed drops down to $91 \%$ of the fixed-demand value, while on the Debnicki bridge it is reduced down to $85 \%$ of the fixeddemand value.

4.5. Peak-Hour Share Growth. As supported by empirical evidence, travellers often tend to shift their departure times to avoid congestion (and thus reduce their travel costs) [7], and consequently their actual departure time may become different from the desired one. This phenomenon is positively correlated with the travel costs, and we can thus expect that when travel costs become lower, travellers will not need to deviate from their desired departure times. 


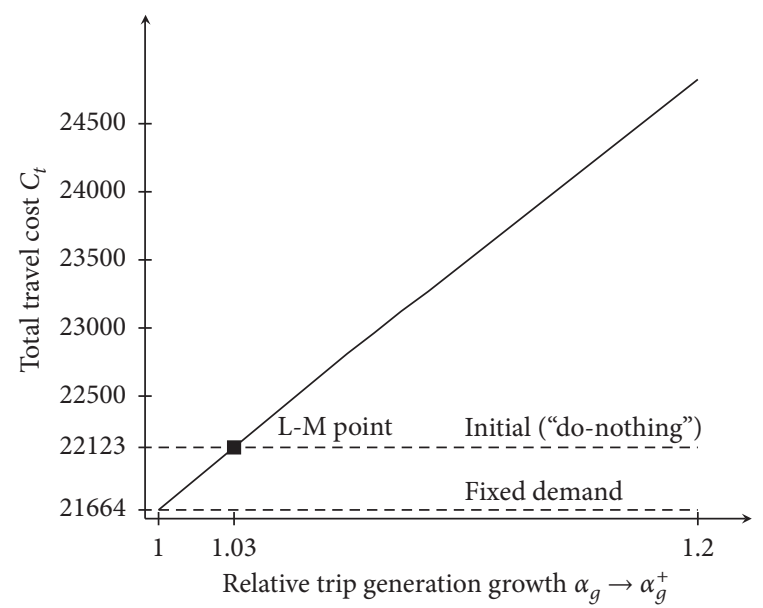

Figure 7: Travel costs $C_{t}$ against trip generation growth.

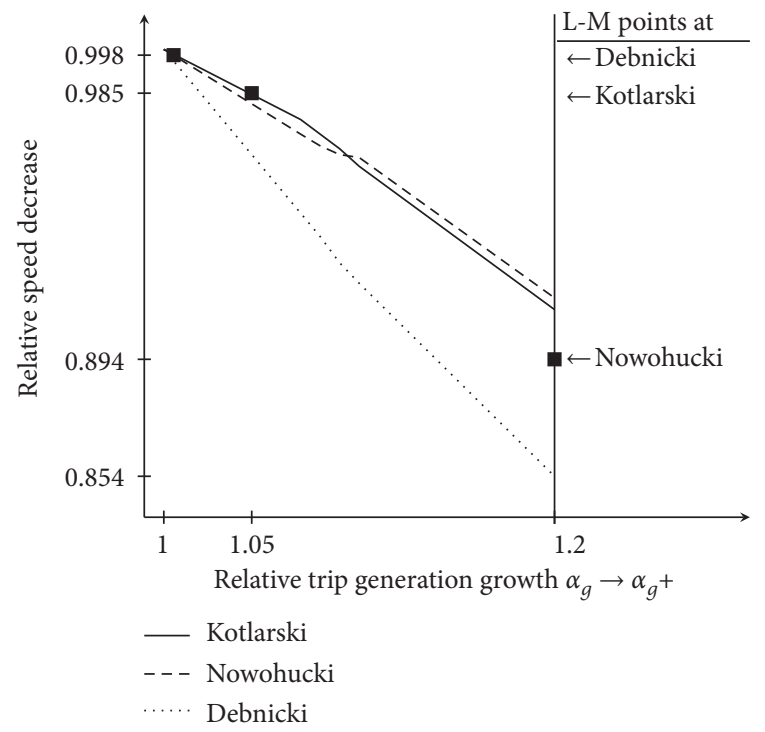

FIGURE 8: Relative speed decrease on alternative bridges against trip generation growth.

We simulate this by multiplying the initial-scenario peak-hour share $\alpha_{h} \longrightarrow \alpha_{h+}$ with the results depicted in Figure 9. The global L-M point is obtained at the $2.45 \%$ peakhour share increase. Unsurprisingly, the results are interdependent with the previous scenarios; i.e., the od matrix is roughly similar if we increase either the population, mobility rate, or peak-hour share. The distance expressed with relative increase of trip numbers is $2.45 \%$, which is greater than $2.0 \%$ obtained for the impact corridor growth; we therefore store the latter as the lowest-distance rate. In this case, the impact of additional trips is global and increases are uniformly distributed over the whole matrix. Again, the difference between the prior scenarios lies in the interpretation, which may be substantially different. More complex results are obtained in the subsequent scenarios.

4.6. Trip Length Growth. Lower travel costs may encourage travelling to further destinations and, in consequence, lead to higher share of long-distance trips. We represent it

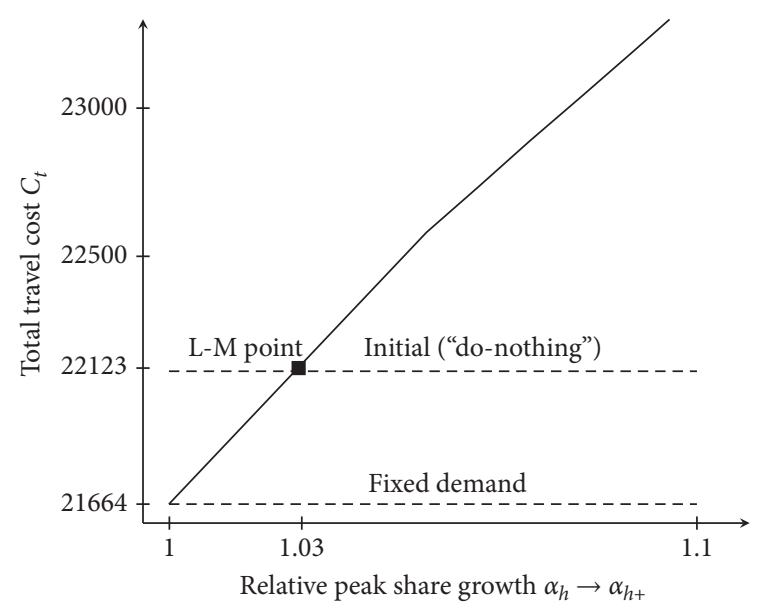

Figure 9: Travel costs $C_{t}$ against peak-hour share growth.

through $\mathbf{c} \longrightarrow \mathbf{c}^{+}$change in equation (6). We gradually decrease the perceived travel cost and find the global Lewis-Mogridge point at the ca. $10 \%$ decrease of travel costs perceived at the trip distribution stage, as depicted in Figure 10. Note that in this case the total number of trips will not change, since trip distribution model changes only their spatial distribution and the respective shares of shorter- and longer-range trips. Consequently, neither the distance between fixed-demand figures nor the distance between induced-demand figures could be measured with equation (21) for this scenario; the same holds for the $\mu$ value.

4.7. Mode Shift towards Cars. In this scenario, we assume that the improved road network will become more attractive and additional trips will shift from alternative modes of transport (especially from public transport). We simulate this simply by multiplying the utility used in equation (7): $\mathbf{U}_{\text {car }} \longrightarrow \mathbf{U}_{\text {car+ }}$. The results (in Figure 11) show that the global L-M point is found at the relative increase in car utility of $7.2 \%$, which translates into ca. $4 \%$ higher number of OD trips. If we use this value to compute distance with equation (21) the corresponding $\mu$ value will remain higher than previously obtained ones.

4.8. Underestimated Impedance of New Road Link. New roads may be subjectively perceived by car drivers as more attractive than other segments of road network. Such phenomena can be reproduced in the model as suboptimal route choices when travel cost of a new road is underestimated. We simulate this by reducing the travel time (equation (2)) (i.e., main factor affecting the route choice model) by a given factor. Results depicted in Figure 12 exhibit a nonlinear trend, which becomes evident when perceived travel costs are 50\% lower. We reach the global L-M point at the unrealistic null travel time of the introduced S7 expressway (i.e., the "teleport" case). In this case, drivers are attracted by the new road regardless of actual congestion levels, which becomes severe enough to consume all the benefits. In this case, the number of trips 


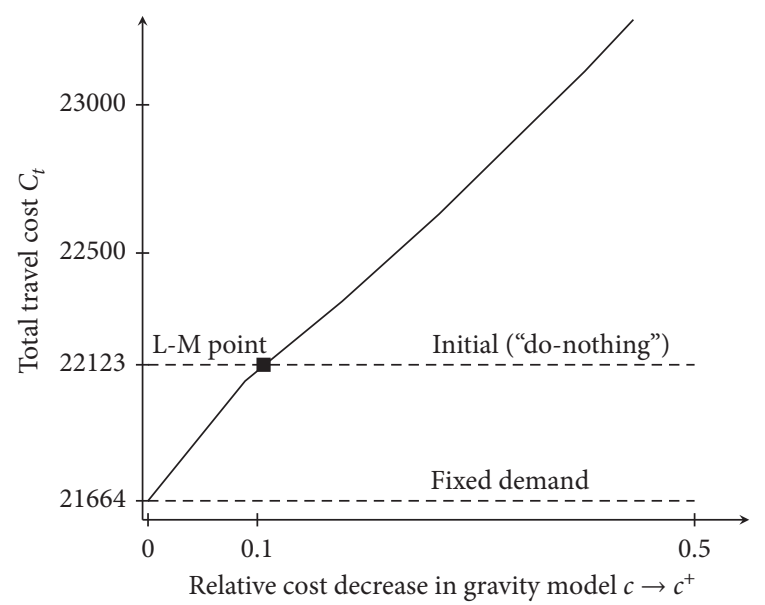

Figure 10: Travel costs $C_{t}$ against relative perceived cost decrease in the gravity model.

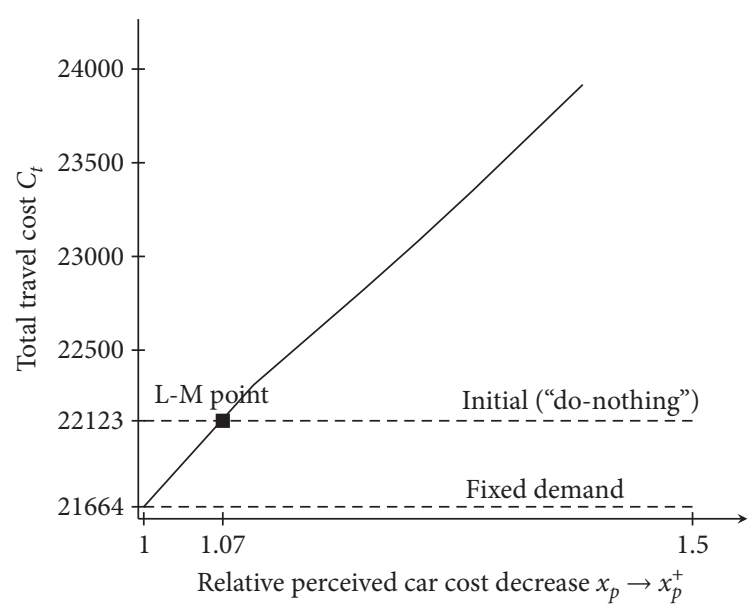

Figure 11: Travel costs $C_{t}$ against relative perceived utility increase in the mode-choice model $\mathbf{U}_{\text {car }} \longrightarrow \mathbf{U}_{\text {car+ }}$.

remains the same, so the distance cannot be determined, as well as the $\mu$ value.

4.9. The $\mu$ Indicator. For simulated scenarios, we found in total seven various L-M points and corresponding demand model modifications $\mathbf{d}^{*}$ reproducing the induced demand phenomenon. For most of them, we were able to evaluate the relative increases in number of trips $\left\|\mathbf{d}, \mathbf{d}^{*}\right\|$ (equation (21)) and the $\mu$ values (equation (20)), as summarised in Table 2 .

In this underdetermined problem, where multiple L-M points are found, it is still unclear which one shall be selected as the reference one and used for further analyses and comparisons. In fact, this requires answering the question on likelihood of respective induced demand scenarios, i.e., is it more likely to increase the population by $2.0 \%$ or peak-hour share by $2.45 \%$ ? In further research, this can be more exploited and supported with some evidence; now we simply use the scenario with lowest relative growth in number of trips. However, since the corridor population growth is investment-dependent, we use $\mu$ of the city-wide population growth scenario as the reference one.

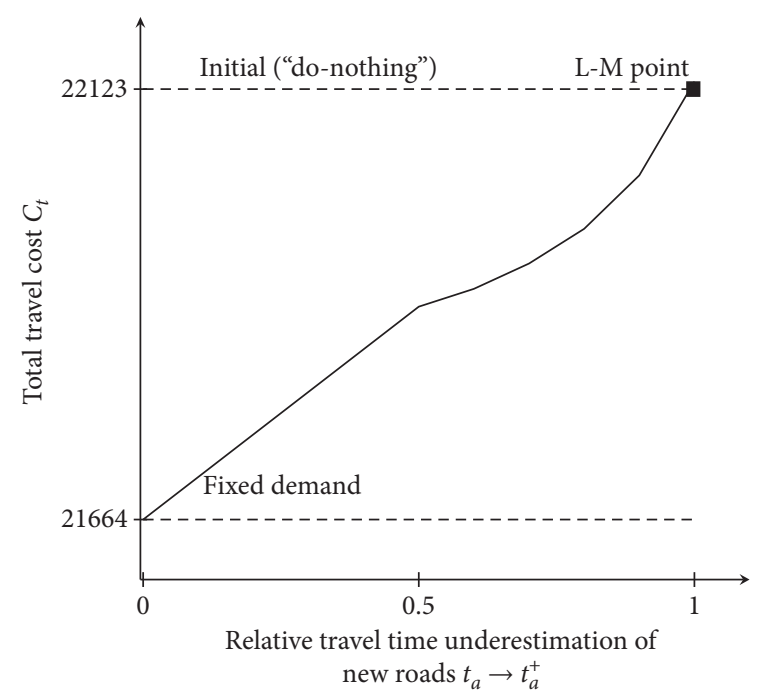

Figure 12: Travel costs $C_{t}$ against relative perceived cost decrease of the new road in the route-choice model.

4.10. Comparing Scenarios with the Proposed Method. One of the key applications of the proposed method would be for scenario comparison purposes, where the Lewis-Mogridge points would be used to evaluate various possible scenarios and select the optimal ones. The proposed L-M and the related $\mu$ indicator can support this decision-making process and serve as a meaningful comparison measure. We illustrate this with the following experiment.

The abovementioned analysis for S7 expressway scenario is now compared with an alternative scenario. We now estimate benefits for the road network improvements scheme, which would bring about similar benefits in terms of total travel time $\left(B_{t}\right)$. The alternative scenario involves completion of the third Krakow ring (RR3), a high-capacity, dual-carriageway route with multilevel junctions encircling the inner (central) part of Krakow (Figure 13). The fixed-demand benefits were comparable and total travel costs $C_{t}$ dropped down by ca. 2000 vehicle-hours, yet if we look at the related Lewis-Mogridge points, we find that the alternative investment (RR3) is significantly less sensitive to induced demand effects (Table 3). The benefits of the RR3 scheme would be totally consumed only by $5.0 \%$ population growth, instead of $2.8 \%$ found for the previous S7 scheme,i.e., these are global $\mathrm{L}-\mathrm{M}$ points values obtained for two respective scenarios. This is a clear indication showing that induced-traffic demand needs to be significantly higher to consume benefits of an alternative improvement (RR3), and the related $\mu$ indicator (equation (20)) is twice higher (21 instead of 12):

$$
\begin{gathered}
\mu_{\mathbf{S} 7}=B_{t}(\mathbf{S} 7) \cdot\left\|\mathbf{d}, \mathbf{d}^{*}\right\|=429 \cdot 0.028=12.01, \\
\mu_{\mathrm{RR} 3}=B_{t}(\mathbf{R R} 3) \cdot\left\|\mathbf{d}, \mathbf{d}^{*}\right\|=426 \cdot 0.05=21.30 .
\end{gathered}
$$

\section{Discussion}

The objective of this paper was to propose an extended approach for assessing the possible benefits of road 
TABLE 2: The L-M points and $\mu$ values found in the analysed scenario.

\begin{tabular}{lccc}
\hline Scenario & Factor $(\%)$ & Distance-relative increase in number of trips $(\%)$ & $\mu$ \\
\hline Population & 2.8 & 2.80 & 7.25 \\
Corridor population & 17 & $\mathbf{2 . 0 4}$ & $\mathbf{5 . 2 8}$ \\
Trip generation & 2.8 & 2.80 & 7.25 \\
Peak-hour share & 2.5 & 2.50 & 6.50 \\
Distance-decay & 10 & - & 10.36 \\
Car utility & 7.2 & 4.00 & - \\
Travel time perception & 100 & - & - \\
\hline
\end{tabular}

TABLE 3: Comparison of benefits of two alternative network improvements.

\begin{tabular}{lccc}
\hline & Scenario & Total travel costs & Benefits \\
& & $C_{t}$ & $B_{t}$ \\
\hline Initial & & 22123 & - \\
S7 & Fixed demand & 21664 & 429 \\
S7 & 2.8\% pop. growth & 22127 & $\approx 0$ \\
\hline RR3 & Fixed demand & 21694 & 426 \\
RR3 & 5\% pop. growth & 22120 & $\approx 0$ \\
\hline
\end{tabular}

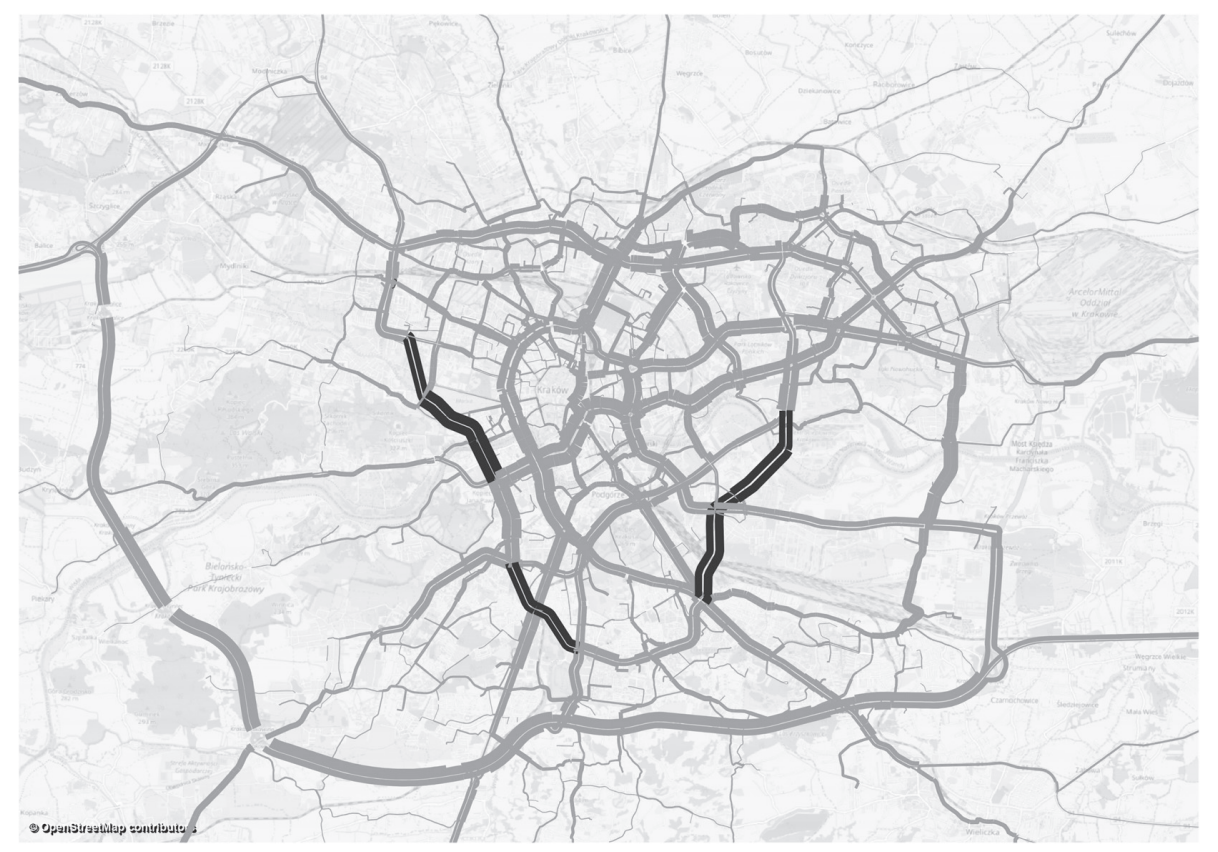

FIgURE 13: Alternative improvement, completion of an inner-city third ring road (RR3) in Krakow with two new bridges crossing the Vistula river (new arcs marked with solid black; bars denote morning peak flow).

improvement schemes, which addresses the issue of their potential erosion due to costs of induced traffic. The method is formulated using the classical Lewis-Mogridge position, where induced traffic demand eventually mitigates all the benefits of road investment schemes. We propose a method that is applicable within the classical four-step model (FSM) for macroscopic trip assignment purposes and demonstrate it for a case study in the Polish city of Kraków (the eastern part of expressway ring road). The objective of the proposed method is to estimate shifts in input (explanatory) variables of four-step demand model, under which the initial (fixeddemand) benefits would be fully diminished by eventual (induced-traffic) costs, i.e., once the so-called Lewis-Mogridge points would be achieved.
Main conclusions from the case study are as follows:

(1) In the fixed-demand scenario, the analysed S7 road scheme indeed brings noticeable road network improvements, which are equal to ca. $2 \%$ reduction in terms of network-wide vehicle-hours compared to the initial ("do-nothing") scenario. Apparently, such improvements in traffic conditions could have a profound impact on the ensuing CBA results.

(2) In further (variable-demand) scenarios, we apply the proposed method and obtain the following set of the global Lewis-Mogridge points, i.e., marginal increases in (global scale) demand model variables, for which travel costs imposed by additional traffic 
demand would mitigate $100 \%$ of the benefits brought about by the S7 scheme: total (city) population increase of $3 \%$, local (direct impact corridor) population increase of $17 \%$, trip generation increase of $3 \%$, peak-hour share increase of 3\%, 10\% lower distance decay in the gravity-based trip distribution model, and $7 \%$ lower perceived car disutility in the mode choice model.

(3) Apart from the global (city-wide) analysis, we also investigate the "local" Lewis-Mogridge points and observe what traffic demand increase would cause traffic speeds on alternative bridge crossings to drop down to preinvestment rates. Results expose much higher variability for each considered demand scenario, as even global-scale changes might induce different traffic speed patterns. For example, traffic speeds on alternative bridges would be more resilient to traffic demand increases in case of trip generation growth than in case of total population growth; furthermore, as it might be expected, demand changes limited to the direct impact corridor would much less affect traffic speeds on the more-distant alternative bridge crossings. Finally, each bridge crossing would exhibit a specific pattern of its local Lewis-Mogridge point, depending on its location in the general network topology, with closer alternative crossings exposing higher rates of Lewis-Mogridge points than further or congested inner-city crossings (e.g., speeds on the Debnicki bridge already achieve their preinvestment levels in the fixed-demand scenario).

(4) Out of the multiple Lewis-Mogridge points, we select the one that yields the lowest relative increase in total number of trips. The benefits become null already for a $2 \%$ increase in total number of trips in the corridor population growth scenario, compared to $2.8 \%$ increase for the trip generation and $4 \%$ decrease in perceived car disutility.

(5) Finally, we demonstrate the applicability of the proposed measure for scenario comparison analysis, where the Lewis-Mogridge points can expose different output sensitivity to induced traffic demand. In our example, the S7 road scheme is compared against an alternative scheme comprising upgrades and improvements along the inner-city ring road (the RR3 scheme). We selected such alternative scenario where the initial benefits are similar to the S7 scenario, yet the proposed method exposed that benefits of the S7 scheme are totally consumed for the $2.8 \%$ population increase rate, whereas, for the alternative scheme, a $5.0 \%$ population increase rate would be required to mitigate all its benefits. This can be captured with a proposed measure $\mu$, which is significantly higher for the more robust scenario.

Limitation of the method lies in undetermined solution provided by the method, showing one parameter of FSM that needs to be changed to obtain Lewis-Mogridge point.
This can be further extended to propose L-M points of composite scenarios where several variables and parameters of demand model are modified simultaneously to obtain more realistic results. Similarly, the probability of L-M points shall be estimated and the ones that are most likely shall be used for further analyses. Another possible direction is to express the L-M points in terms of demand elasticity corresponding to changes of demand model.

The proposed method can be utilised in transport modelling practice to extend the scope of conventional induced traffic demand: by reversing the common question in induced demand analysis, it focuses instead on evaluating the exact scale of demand input changes which would lead to the Lewis-Mogridge paradox of diminishing all the road network benefits. The proposed Lewis-Mogridge points can be evaluated either on the global scale or more locally to inspect the performance of isolated network elements. Moreover, the proposed method is directly applicable for scenario comparison and sensitivity analysis of various road development schemes to eventual induced traffic effects.

\section{Data Availability}

There is no dataset available for this research. The strategic demand model that we used is IP protected. Requests for access to it should be made to corresponding author

\section{Additional Points}

(1) Road network improvement schemes typically generate induced traffic demand. (2) We introduce the so-called Lewis-Mogridge points of road improvement at which costs of induced demand outweigh the initial benefits. (3) This allows to both include the induced traffic in the analysis and avoid arbitrary assumptions on the induced traffic. (4) We illustrate the proposed method by comparing two alternative network improvements of similar benefits, yet different resilience, to induced demand.

\section{Conflicts of Interest}

The authors declare that there are no conflicts of interest regarding the publication of this paper.

\section{Acknowledgments}

This paper was developed within R\&D project RID2A "trip modelling and forecasting using different modes of transport" financed by the National Centre for Research and Development and National Roads and Motorway Administration in Poland.

\section{References}

[1] M. C. González, C. A. Hidalgo, and A.-L. Barabási, "Understanding individual human mobility patterns," Nature, vol. 453, no. 7196, pp. 779-782, 2008.

[2] R. Hickman, P. Hall, and D. Banister, "Planning more for sustainable mobility," Journal of Transport Geography, vol. 33, pp. 210-219, 2013. 
[3] D. Esztergár-Kiss, "System architecture of the activity chain optimization application," in Proceedings of the 2017 5th IEEE International Conference on Models and Technologies for Intelligent Transportation Systems (MT-ITS), pp. 415-420, Naples, Italy, June 2017.

[4] A. Szarata, Modelowanie Podrozy Wzbudzonych Oraz Tlumionych Zmiana Stanu Infrastruktury Transportowej, Politechnika Krakowska, Kraków, Poland, 2014.

[5] T. Litman, Generated Traffic and Induced Travel, Vol. 22, Victoria Transport Policy Institute, Victoria, Canada, 2001.

[6] R. B. Noland, "Transport planning and environmental assessment: implications of induced travel effects," International Journal of Sustainable Transportation, vol. 1, no. 1, pp. 1-28, 2007.

[7] R. Gorham, Demystifying Induced Travel Demand, Bundesministerium fuer wirtschaftliche Zusammenarbeit und Entwicklung, Bonn, Germany, 2009.

[8] P. Bonsall, "Can induced traffic be measured by surveys?" Transportation, vol. 23, pp. 17-34, 1996.

[9] E. Cascetta and P. Coppola, "High Speed Rail (HSR) induced demand models," Procedia-Social and Behavioral Sciences, vol. 111, pp. 147-156, 2014.

[10] R. M. González and G. A. Marrero, "Induced road traffic in Spanish regions: a dynamic panel data model," Transportation Research Part A: Policy and Practice, vol. 46, no. 3, pp. 435445, 2012.

[11] A. Downs, Stuck in Traffic: Coping with Peak-Hour Traffic Congestion, Brookings Institution Press, Washington, DC, USA, 1992.

[12] T. Lin, D. Wang, and M. Zhou, "Residential relocation and changes in travel behavior: what is the role of social context change?," Transportation Research Part A: Policy and Practice, vol. 111, pp. 360-374, 2018.

[13] M. A. Niedzielski and R. Kucharski, "Impact of commuting, time budgets, and activity durations on modal disparity in accessibility to supermarkets," Transportation Research Part D: Transport and Environment, vol. 75, pp. 106-120, 2019.

[14] Z. Chen, J. Xue, A. Z. Rose, and K. E. Haynes, "The impact of high-speed rail investment on economic and environmental change in China: a dynamic CGE analysis," Transportation Research Part A: Policy and Practice, vol. 92, pp. 232-245, 2016.

[15] P. B. Goodwin, "Empirical evidence on induced traffic," Transportation, vol. 23, pp. 35-54, 1996.

[16] D. Coombe, "Induced traffic: what do transportation models tell us?," Transportation, vol. 23, pp. 83-101, 1996.

[17] M. J. Mogridge, "The self-defeating nature of urban road capacity policy: a review of theories, disputes and available evidence," Transport Policy, vol. 4, no. 1, pp. 5-23, 1997.

[18] A. Downs, "The law of peak-hour expressway congestion," Traffic Quarterly, vol. 16, 1962.

[19] J. M. Thomson and J. Thomson, Great Cities and Their Traffic, JSTOR, Ann Arbor, MI, USA, 1977, https://trid.trb.org/view/ 1206556, https://www.amazon.com/Great-cities-trafficMichael-Thomson/dp/0575021462https://scholar.google.pl/ scholar?hl=pl\&as_sdt=0\%2C5\&q=great+cities+and+their+ traffic\&btnG $=\&$ oq $=$ great + cities + .

[20] D. Lewis, "Estimating the influence of public policy on road traffic levels in Greater London," Journal of Transport Economics and Policy, vol. 46, no. 3, pp. 155-168, 1977.

[21] M. J. Mogridge, Travel in Towns: Jam Yesterday, Jam Today and Jam Tomorrow?, Springer, Berlin, Germany, 1990.

[22] G. Fields, D. Hartgen, A. Moore, and R. W. Poole Jr., "Relieving congestion by adding road capacity and tolling,"
International Journal of Sustainable Transportation, vol. 3, no. 5-6, pp. 360-372, 2009.

[23] M. Nourinejad and M. J. Roorda, "Impact of hourly parking pricing on travel demand," Transportation Research Part A: Policy and Practice, vol. 98, pp. 28-45, 2017.

[24] S. Zhong and M. Bushell, "Impact of the built environment on the vehicle emission effects of road pricing policies: a simulation case study," Transportation Research Part A: Policy and Practice, vol. 103, pp. 235-249, 2017.

[25] L. Kröger, T. Kuhnimhof, and S. Trommer, "Does context matter? a comparative study modelling autonomous vehicle impact on travel behaviour for Germany and the USA," Transportation Research Part A: Policy and Practice, vol. 122, pp. 146-161, 2018.

[26] D. J. Graham and S. Glaister, "Road traffic demand elasticity estimates: a review," Transport Reviews, vol. 24, no. 3, pp. 261-274, 2004.

[27] R. B. Noland, "Relationships between highway capacity and induced vehicle travel," Transportation Research Part A: Policy and Practice, vol. 35, no. 1, pp. 47-72, 2001.

[28] R. G. Schiffer, M. W. Steinvorth, and R. T. Milam, "Comparative evaluations on the elasticity of travel demand," in Proceedings of the TRB 2005 Annual Meeting, Washington DC, USA, January 2005.

[29] W. Davies, "What effect do queensland's major road infrastructure projects have on traffic volumes and growth rates?," in Proceedings of the Australasian Transport Research Forum 2015 Proceedings, vol. 30, Sydney, Australia, September-October 2015.

[30] C. J. Rodier, J. E. Abraham, R. A. Johnston, and J. D. Hunt, "Anatomy of induced travel using an integrated land use and transportation model in the sacramento region," in Proceedings of the 80th Annual Meeting of the Transportation Research Board, Washington DC, USA, 2001.

[31] P. J. Mackie, "Induced traffic and economic appraisal," Transportation, vol. 23, pp. 103-119, 1996.

[32] H. C. Williams and L. A. Moore, "The appraisal of highway investments under fixed and variable demand," Journal of Transport Economics and Policy, vol. 24, pp. 61-81, 1990.

[33] H. C. W. L. Williams, D. Van Vliet, and K. S. Kim, "The contribution of suppressed and induced traffic in highway appraisal, part 2: policy tests," Environment and Planning A: Economy and Space, vol. 33, no. 7, pp. 1243-1264, 2001.

[34] P. Ness, M. S. Nicolaisen, and A. Strand, "Traffic forecasts ignoring induced demand: a shaky fundament for cost-benefit analyses," European Journal of Transport and Infrastructure Research, vol. 12, pp. 291-309, 2012.

[35] H. C. Williams and Y. Yamashita, "771 Travel demand forecasts and the evaluation of highway schemes under congested conditions," Journal of Transport Economics and Policy, vol. 26, no. 3, pp. 261-282, 1992, https://www.jstor.org/ stable/20052987?seq=1.

[36] J. G. Wardrop, "Road Paper. Some theoretical aspects of road traffic research," Proceedings of the Institution of Civil Engineers, vol. 1, no. 3, pp. 325-362, 1952.

[37] R. Kucharski and A. Drabicki, "Estimating macroscopic volume delay functions with the traffic density derived from measured speeds and flows," Journal of Advanced Transportation, vol. 2017, Article ID 4629792, 10 pages, 2017.

[38] G. Gentile et al., "The general link transmissionmodel for dynamic network loading and a comparison with the DUE algorithm," New Developments in Transport Planning: Advances in Dynamic Traffic Assignment, vol. 178, p. 153, 2010. 
[39] M. Balmer, K. Meister, M. Rieser, K. Nagel, and K. W. Axhausen, "Agent-based simulation of travel demand," Arbeitsbericht Verkehrs-Und Raumplanung, vol. 504, 2008.

[40] M. Van Essen, T. Thomas, E. van Berkum, and C. Chorus, "From user equilibrium to system optimum: a literature review on the role of travel information, bounded rationality and non-selfish behaviour at the network and individual levels," Transport Reviews, vol. 36, no. 4, pp. 527-548, 2016.

[41] A. Ermagun, Y. Fan, J. Wolfson, G. Adomavicius, and K. Das, "Real-time trip purpose prediction using online locationbased search and discovery services," Transportation Research Part C: Emerging Technologies, vol. 77, pp. 96-112, 2017.

[42] A. Szarata, "Wyniki badań podróż w Krakowie-KBR 2013," Transport Miejski I Regionalny, vol. 4-8, 2015.

[43] M. Lenormand, A. Bassolas, and J. J. Ramasco, "Systematic comparison of trip distribution laws and models," Journal of Transport Geography, vol. 51, pp. 158-169, 2016. 